\title{
PREVALÊNCIA DE EHRLICHIOSE CANINA ENTRE ANIMAIS ATENDIDOS NO COMPLEXO HOSPITALÁRIO VETERINÁRIO DO COROZAL, FACULDADE DE MEDICINA VETERINÁRIA, UNIVERSIDADE DE PANAMÁ
}

\author{
A. Perez, E. Pile*, A. Torres, J. Lasso \\ Universidad de Panamá, Facultad de Medicina Veterinaria, Av. Omar Torrijos, Altos de Curundu, Cor- \\ regimiento de Ancón, Panamá, Rep. de Panamá.
}

\section{RESUMO}

\begin{abstract}
Foi determinada a prevalência de Ehrlichiose canina entre animais atendidos no Complexo Hospitalário Veterinário do Corozal da Faculdade de Medicina Veterinária da Universidade de Panamá. O levantamento foi realizado de forma retrospectiva com dados obtidos no período de janeiro de 2004 a dezembro de 2009. Para o trabalho, foram utilizados os registros dos casos clínicos de ehrlichiose canina, confirmados através de esfregaço sanguíneo, a raça e os aspectos demográficos (idade, sexo e local de origem) de cada animal. Os resultados revelaram que $10,12 \%$ dos animais atendidos $(\mathrm{n}=1.452)$ mostraram-se positivos para o problema no período em análise. Esses animais eram de ambos os sexos com idade media de aproximadamente 3,6 anos. A prevalência mensal registrada foi de 9,98\%, com taxa de infecção significativamente superior em 2008 (14,83\%). O número de casos positivos foi significativamente superior nos meses de março, maio e setembro e menor no mês de fevereiro, destacando-se haver densidade de casos igual ou superior à média de maio a outubro. A raça e o local de origem dos animais foram identificados como fatores de risco.
\end{abstract}

PALAVRAS-CHAVE: Rickettsias, Ehrlichia, ehrlichiose, cães.

\section{ABSTRACTS}

PREVALENCEOFCANINEEHRLICHIOSISAMONGANIMALSTREATEDATTHECOROZAL VETERINARY HOSPITAL OF THE FACULTY OF VETERINARY MEDICINE, UNIVERSITY OF PANAMA. The aim of this study was to determine the prevalence of canine Ehrlichiosis among animals treated at the Corozal Veterinary Hospital of the Faculty of Veterinary Medicine, University of Panama, Brazil. The survey was conducted retrospectively with data obtained from January 2004 to December 2009, based on the records of clinical cases of canine ehrlichiosis, confirmed with blood smear, race and demographics data (age, sex and place of origin) of each animal. The results revealed that $10.12 \%$ of the treated animals $(n=1452)$ were positive in the period under review. These animals were of both sexes with a mean age of approximately 3.6 years. The monthly prevalence recorded was $9.98 \%$, with a significantly higher infection rate in 2008 (14.83\%). The positive cases were significantly higher in the months of March, May and September and lowest in February, with a noteworthy density of cases equal to or higher than the average from May to October. Breed and place of origin of the animals were identified as risk factors.

KEY WORDS: Rickettsias, Ehrlichia, ehrlichiosis, dogs.

A Ehrlichiose canina, também conhecida como rickettsiose canina, febre hemorrágica canina, tifo canino, doença dos cães perdigueros e pancitopenia canina tropical, é uma doença geralmente transmitida por carrapatos e causada por agentes da Febre Maculosa do grupo rickettsia (SFGR), geralmente Ehrlichia canis. Estes são agentes de ampla distribuição geográfica, registrados particularmente em áreas tropicais e subtropicais, que podem infectar humanos quando expostos a carrapatos infectados (ETTINGER; FeLDMAN, 1995).
Recentemente, tem sido registrada a ocorrência de diversos surtos de rickettsioses em comunidades colombianas localizadas próximas à fronteira com a República do Panamá. Os resultados dessas publicações indicaram que de 289 carrapatos, coletados em $2007,37,4 \%$ resultaram positivos para agentes da SFGR, incluindo 20,3\% Rhipicephalus sanguineus, 27,9\% Amblyomma ovale, 25,8\% Dermacentor nitens, $50 \%$ R. microplus, $50 \%$ A. oblongoguttatum e $100 \%$ A. cajennense. A presença de DNA de Rickettsia amblyommii foi confirmada por sequenciamento em

*Sistema Nacional de Investigación (SNI - SENACYT). 
A. cajennense, A. oblongoguttatum, A. ovale, B. microplus e $R$. sanguineus. A de DNA de $R$. rickettsii foi somente detectada em um espécime de $D$. nitens coletado de um cavalo em Santa Fé, Provincia de Darién. DNA de $E$. chaffensis foi registrado em 3 espécimes de $D$. nitens e 3 de $A$. cajennense provenientes de cavalos (Bermudez et al., 2009; EREMEeva et al., 2009).

Por outro lado, a presença de Rickettsia spp. (Determinada através de técnicas de imunofluorescência e PCR) foi avaliada em ectoparasitos coletados de cavalos e cães provenientes de comunidades de El Valle de Antón, Penonomé, Provincia de Coclé. Os autores amostraram 40 animais, sendo 20 equinos e 20 caninos, registrando quatro espécies deectoparasitos em cães ( $R$. sanguineus, A. ovale, A. oblongoguttatum e Ctenocephalides felis), e duas espécies nos equinos (A. cajennense e D. nitens). DNA de R. amblyommii foi encontrado em homogeneizados de A. cajennense, D. nitens e R. sanguineus, enquanto $R$. felis foi detectada em homogeneizados de $C$. felis. Os resultados demonstraram que $70 \%(14 / 20)$ e $65 \%(13 / 20)$ dos equinos e caninos, respectivamente, resultaram seroreativos (título $\geq 64$ ) para SFGR, sendo que soros de 6 cães e 5 equinos reagiram a antígenos de $R$. amblyommii com títulos, no mínimo, quatro vezes superiores a outros antígenos testados para R. bellii, R. parkeri, $R$. rhipicephali, R. felis, e R. rickettsii (BERMUDEZetal., 2011). Considerando estes resultados, este levantamento foi realizado no intuito de verificar a presença de ehrlichiose canina, indicativo da presença deagentes da SFGR, entre animais que convivem em ambiente familiar e atendidos no Complexo Hospitalário Veteri-nário, e ressaltar, desta forma, o potencial zoonótico que este fato representa.
Olevantamento foi realizado de forma retrospectiva com dados obtidos, no período de janeiro de 2004 a dezembro de 2009, no Complexo Hospitalário Veterinário del Corozal, Faculdade de Veterinária da Universidade de Panamá. Para o trabalho, foram utilizados os registros dos casos clínicos de Ehrlichiose canina, com confirmação através de esfregaço de sangue perisférico. A raça e os aspectos demográficos (idade, sexo e local de origem) dos casos também foram registrados.

Os resultados revelaram que $10,12 \%$ dos animais atendidos $(n=1.452)$ mostraram-se positivos para o problema, no período em análise (20042009). Esses animais eram de ambos os sexos X2; p > 0:05 (om idade media de 3,58 anos (Fig. 3). A prevalência mensal registrada foi de $9,98 \%$, com taxa de infecção significativamente superior em 2008 (14,83\%) (Fig. 1). O problema foi identificado em SRD (19\%), Labrador (7\%), Rottweiler (5\%), American Pitbull (5\%), Cocker Spaniel (4\%), Doberman (3\%), Pequi-poodle (3\%), Chihuahua (3\%), Pastor Alemão (3\%), Dálmata (2\%), Husky Siberiano (2\%), Boxer (1\%), Bulldog Americano (1\%), Pastor Belga (1\%), Pastor Inglés (1\%), Pequinês (1\%), Shih tzu (1\%), Basset Hound (1\%), Beagle $(1 \%)$, French Poodle (1\%), Golden Retriever (1\%), HC (1\%), Perche M. (1\%), Pug (1\%) e Schnauzer (1\%) (29\% das raças não foram identificadas) de proprietários residentes nos distritos $(92 \%$ dos casos não foram registrados) de Balboa (3,58\%), Panamá (2,69\%), Arraiján (1,03\%), San Miguelito $(0,28 \%)$ y La Chorrera $(0,21 \%)$, Entretanto, a procedência de $2,34 \%$ dos casos positivos não foi determinada (Fig. 4).

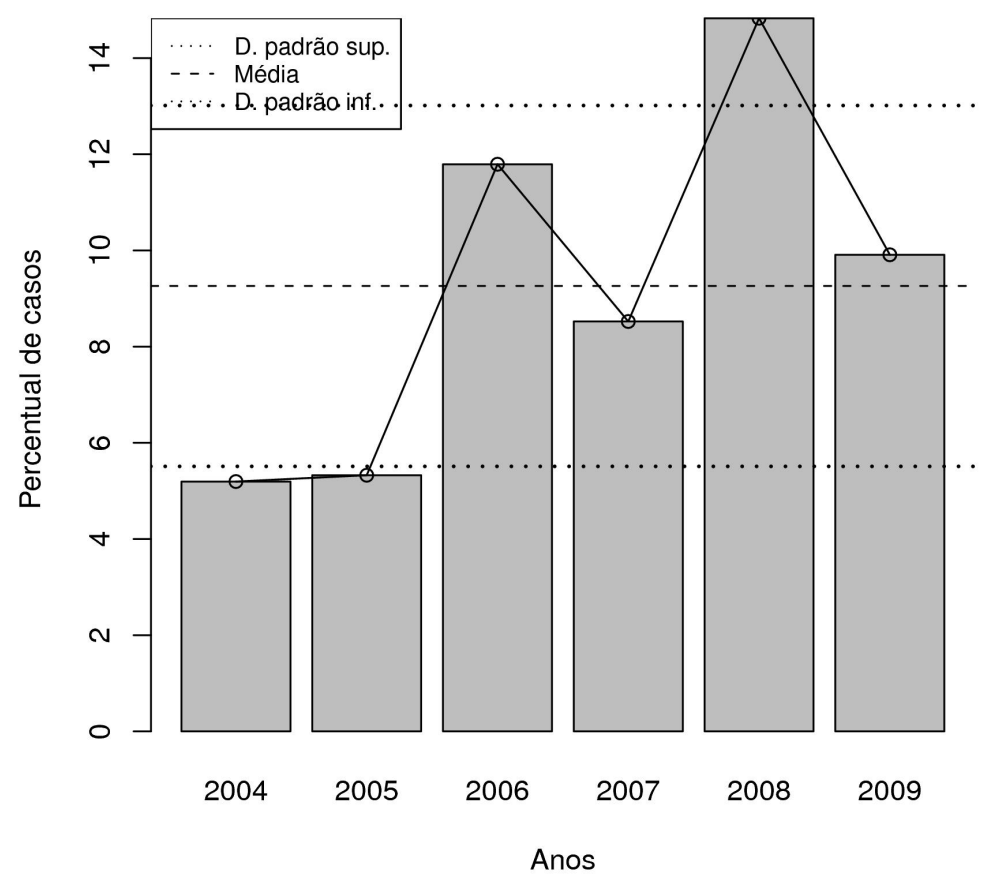

Fig. 1 - Evolução do registro de casos de Ehrlichiose canina no período de 2004 a 2009, Complexo Hospitalário del Corozal. 


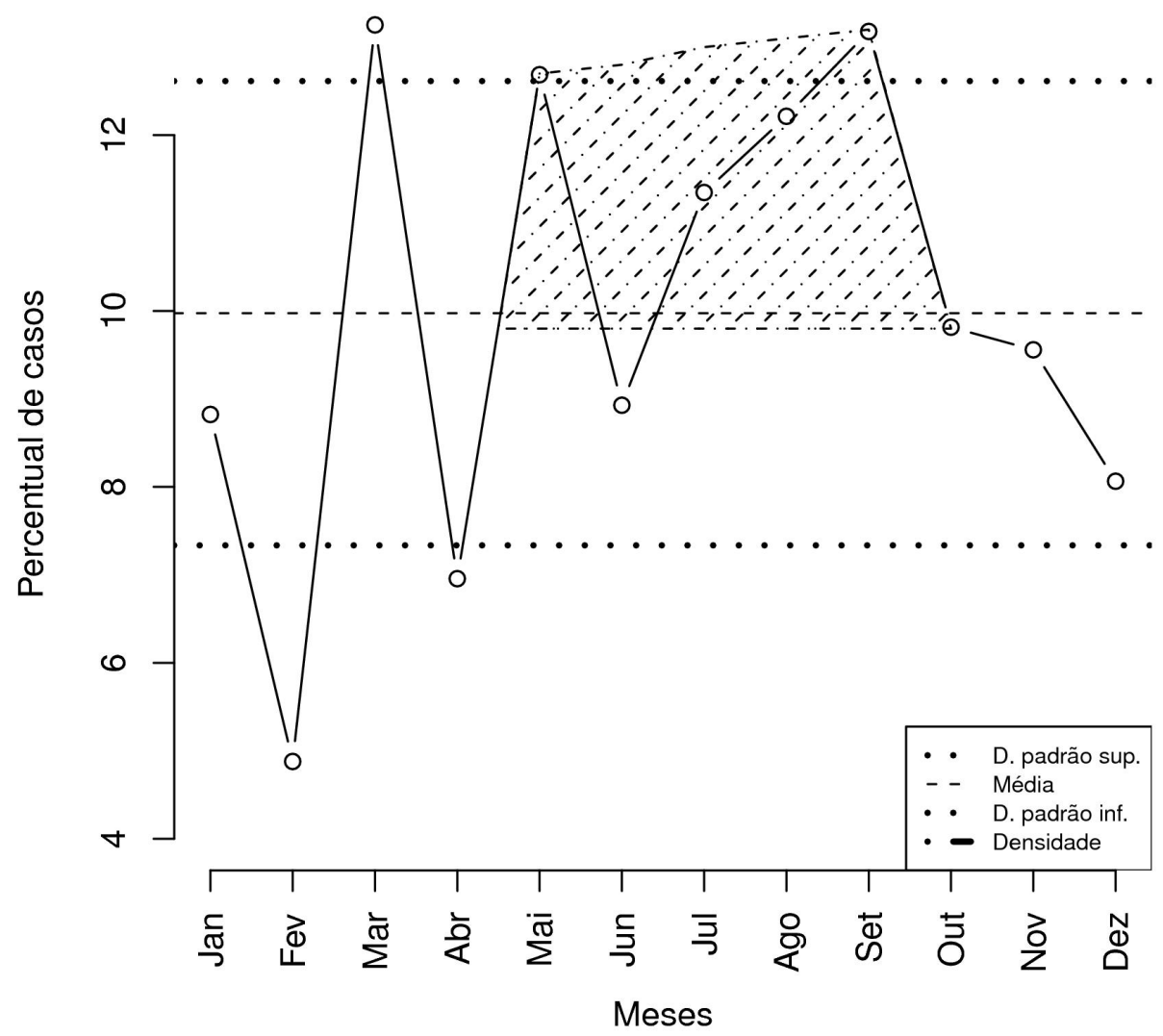

Fig. 2 - Representação gráfica da sazonalidade da Ehrlichiose canina entre animais atendidos no Complexo Hospitalário del Corozal (período 2004 a 2009).

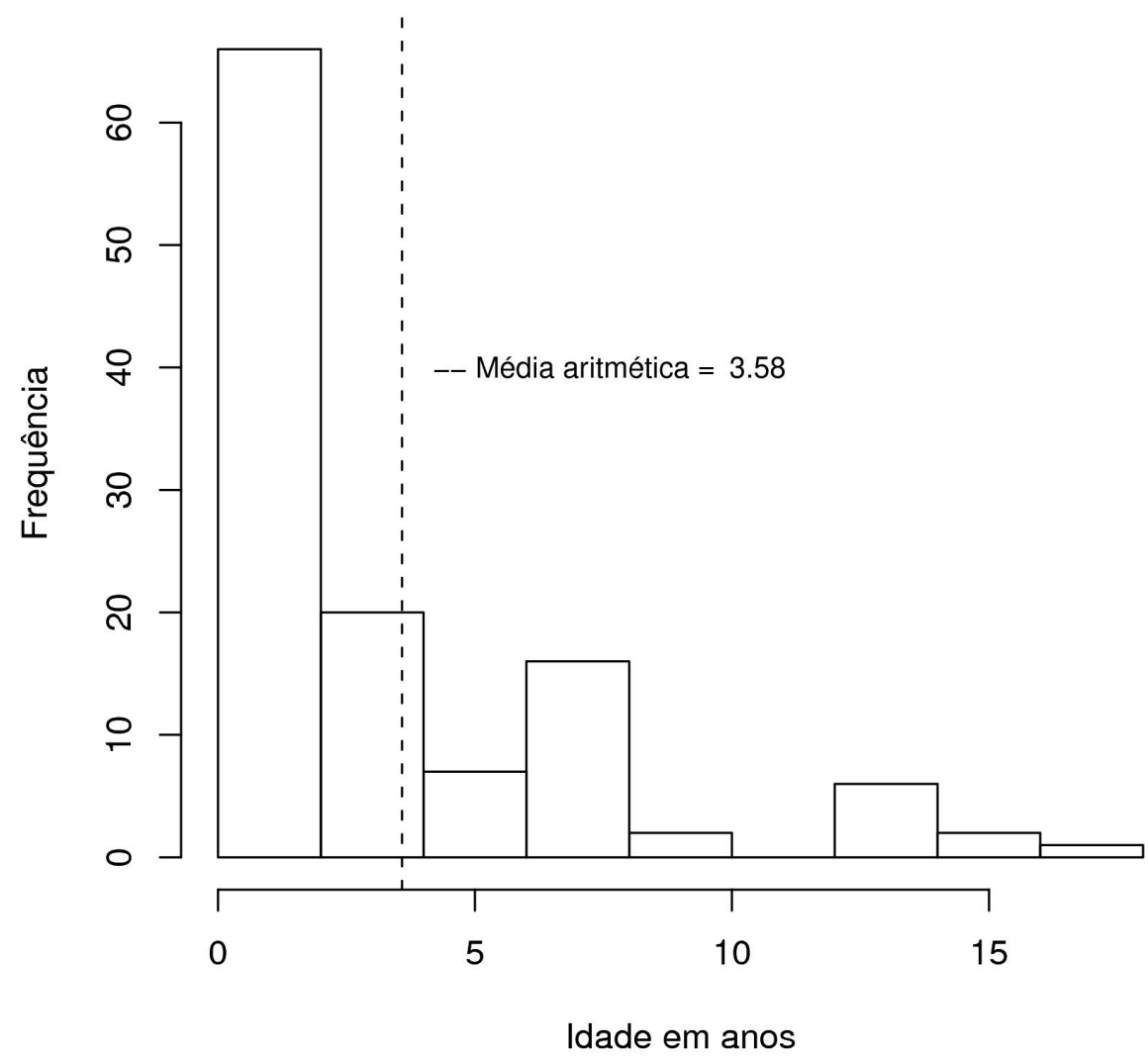

Fig. 3 - Histograma da idade dos animais positivos para Ehrlichisose canina. Dados obtidos de forma retrospectiva no Complexo Hospitalário Veterinário do Corozal (período 2004 - 2009). 


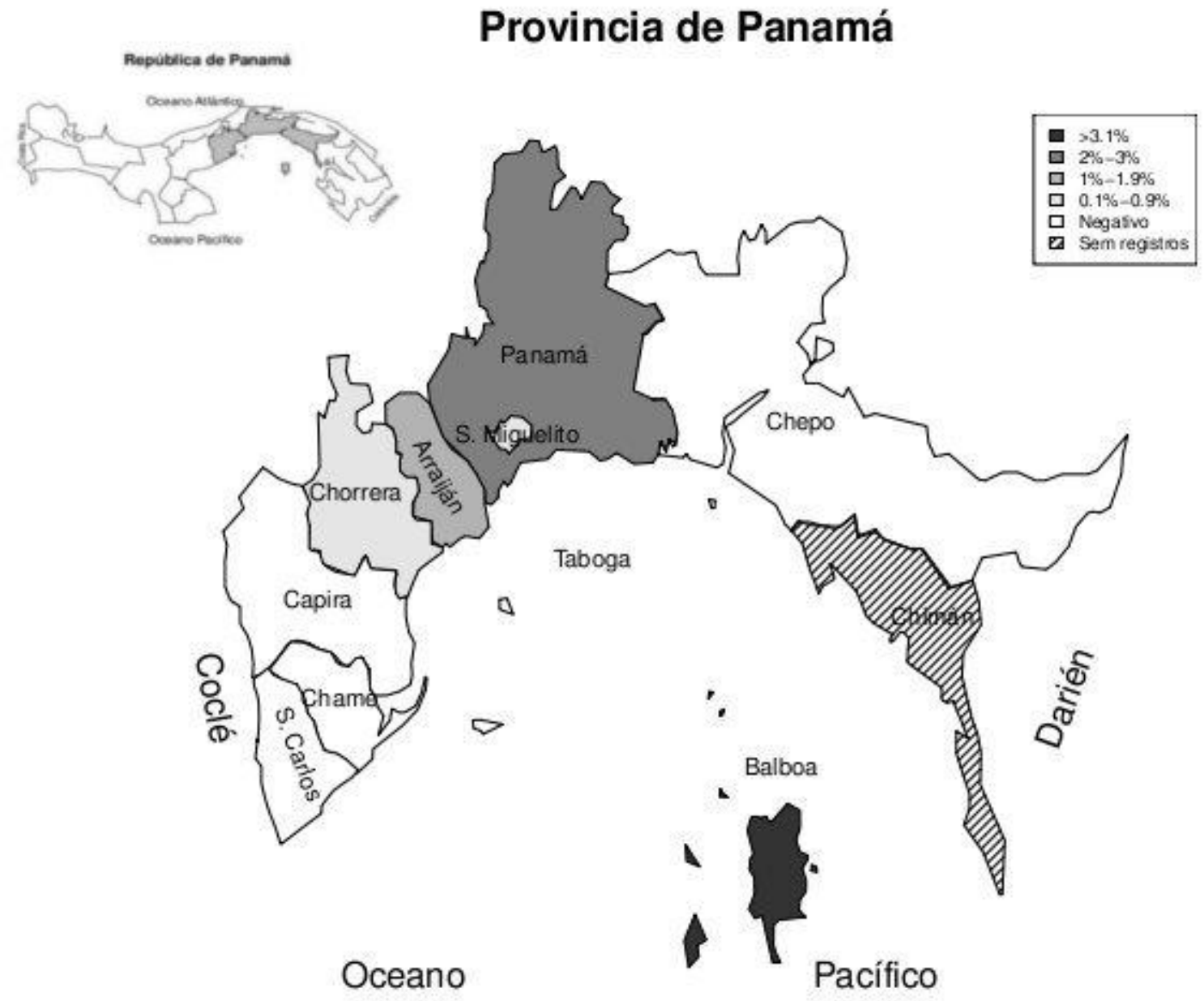

Fig. 4 - Representação gráfica da taxa de ocorrência da Ehrlichiose canina na provincia do Panamá.

A prevalência mensal do problema, também indicada na Figura 2, registra taxas significativamente superiores nos meses de março, maio e Setembro ( $>$ índice $=13,25 \%$ ) e menores no mês de Fevereiro $(4,88 \%)$, destacando-se haver densidade de casos igual ou superior à média de maio a outubro. Os resultados também ressaltam que as raças American Pitbull e Pequi-poodle procedentes do distrito do Panamá foram mais predisponentes ao problema (GLM, pGLM, p_0,05) 0,05) (Tabela 1).

$\mathrm{O}$ resultado demonstrou um aumento considerável, tornando-se significativo, do número de casos positivos, nos últimos quatro anos. Note-se que esses casos ocorreram principalmente entre animais jovens, contudo, a idade não foi um fator de risco. A condição de serem animais de companhia e jovens sugere a presença do vetor no domicílio ou peridomicílio e, portanto, a possibilidade do contato dos vetores com os proprietários.

Da mesma forma, notam-se que animais de pequeno porte, como o Pequi-poodle, estão se tornando mais predisponentes ao problema e que a taxa de ocorrência foi superior nos distritos da zona Este da província (Balboa e Panamá). Este fato sugere um avanço na distribuição espacial do vetor, em direção Este-Oeste. A indicação da presença do(s) vetor(es) nestas zonas é reforçada pelo fato de que, entre aqueles animais que receberam assistência por apresentar problemas hematológicos, 92\% resultaram positivos ao esfregaço sanguíneo. Ainda pelo fato desta forma de diagnóstico ser de baixa sensibilidade, sugere-se uma subestimação do número dos casos registrados.

No Brasil, cita-se ser R. sanguineus o principal vetor nas áreas urbanas, mas pouco se sabe sobre sua ocorrência, transmissãoe outros aspectos epidemiológicos emáreas rurais onde outros vetores foram registrados de forma mais frequente (MOREIRA et al., 2003), sendo que esta diversidade parasitária já tem sido citada no país (BERMUDEZ et al ., 2009). Em relação ao hospedeiro vertebrado, COsTA et al. (2007) demonstraram que em áreas rurais os animais são mais afetados do que em outras regiões e que animais machos, com idades superiores a cinco anos, infectados com carrapatos, foram aqueles com maior predisposição ao problema. Nossos resultados discordam dos desses autores, fato que pode ser explicado pela domiciliação desses animais nas zonas urbanas, pois, neste caso, a presença do vetor se faria notar nos animais de escolha dos proprietários, animais jovens de pequeno porte. 
Tabela 1 - Resultado da análise de variância. Dados obtidos de forma retrospectiva (2004 - 2009) no Complexo Hospitalário Veterinário do Corozal.

\begin{tabular}{lrccc}
\hline & Gl & Desvio & Resíduo Gl & Resíduo desvio \\
\hline Nulo & & & 1165 & 772,93 \\
Raça & 53 & 63,51 & 1112 & 709,42 \\
Corregimiento & 9 & 12,26 & 1103 & 697,16 \\
Sexo & 1 & 0,12 & 1102 & 697,04 \\
Edad & 1 & 0,48 & 1101 & 696,56 \\
Ano & 1 & 5,31 & 1100 & 691,25 \\
Meses & 11 & 9,78 & 1089 & 681,48 \\
\hline
\end{tabular}

Por outrolado, SiLva-Souzaetal. (2010), trabalhando no nordeste do Brasil, demonstraram que entre cães soropositivos para rickettsioses somente um terço $(34,5 \%)$ foram PCR-positivos para E. canis, encontrando-se espécimes de $R$. sanguineus em pelo menos um quinto $(21,9 \%)$ desses animais, o que demonstra a diversidade de agentes e vetores que poderiam estar envolvidos neste quadro.

Desta forma, deixa-se a indicação do aumento significativo da ehrlichiose canina, nos últimos anos, nos corregimentos dos diversos distritos da província do Panamá, do avanço na sua distribuição espacial no sentido Este-Oeste e da predisposição do problema também entre animais de pequeno porte nas zonas urbanas da cidade, mostrando-se assim a necessidade de estudos espidemiológicos para melhor entendimento do comportamento do(s) vetor(es) e agentes, que poderiam estar envolvidos nestequadro, edos riscosquea(s) presença(s) deste(s) poderá (ão) acarretar para a saúde pública.

\section{REFERÊNCIAS}

BERMUDEZ, S.E.; EREMEEVA, M.E.; KARPATHY, S.E.; SAMUDIO, F.; ZAMBRANO, M.L.; ZALDIVAR, Y. Detection and identification of rickettsial agents in ticks from domestic mammals in Eastern Panama. Journal of Medical Entomology, v.46, p.4, p.856-861, 2009.

BERMUDEZ, C.S.E.; ZALDIVAR, A.Y.; SPOLIDORIO, M.G.; MORAES-FILHO, J.; MIRANDA, R.J.; CABALLERO, C.M. Rickettsial infection in domestic mammals and their ectoparasites in El Valle de Antón, Coclé, Panamá. Veterinary Parasitology, v.177, n.1/2, p.134-
138, 2011. Disponível em: http://dx.doi.org/10.1016/j. vetpar.2010.11.020

COSTA, L.M.; REMBECK, K.; RIBEIRO, M.F.B.; BEELITZ, P.; PFISTER, K.; PASSOS, L.M.F. Sero-prevalence and risk indicators for canine ehrlichiosis in three rural areas of Brazil. Veterinary Journal, v.174, n.3, p.673-676, 2007. Disponível em: http://dx.doi.org/10.1016/j. tvj1.2006.11.002

EREMEEVA, M.E.; KARPATHY, S.E.; LEVIN, M.L.; CABALLERO, C.M.; BERMUDEZ, S.; DASCH, G.A. Spotted fever rickettsiae, Ehrlichia and Anaplasma, in ticks from peridomestic environments in Panama. Clinical Microbiology and Infection, v.15, p.12-14, 2009. Supplement 2. Disponível em: http://dx.doi.org/10.1111/j.14690691.2008.02638.x

ETTINGER, S.J.; FELDMAN, E.C. Textbook of veterinary internal medicine. 4.ed. Philadelphia: W.B. Saunders Company, 1995.

MOREIRA, S.; BASTOS, C.; ARAÚJO, R.; SANTOS, M.; PASSOS, L. Retrospective study (1998-2001) on canine ehrlichosis in Belo Horizonte, MG, Brazil. Arquivo Brasileiro de Medicana Veterinária e Zootecnia, v.55, n.2, p.141-147, 2003. Disponível em: http://dx.doi. org/10.1590/S0102-09352003000200003

SILVA SOUZA, B.; LEAL, D.; BARBOZA, D.; UZÊDA, R.; ALCÂNTARA, A. de; FERREIRA, F. Prevalence of ehrlichial infection among dogs and tick in Northeastern Brazil. Revista Brasileira de Parasitologia Veterinária, v.19, n.2, p.89-83, 2010.

Recebido em 2/4/12

Aceito em 18/4/13 